\title{
KARAKTERISTIK PERKEMBANGAN BAHASA SISWA SEKOLAH DASAR
}

\author{
Nurhidayati $^{1}$, Neviyarni Suhaili ${ }^{2}$, Irda Murni ${ }^{3}$ \\ Fakultas Ilmu Pendidikan Universitas Negeri Padang \\ e-mail: Nurhidayati07653@ @mail.com ${ }^{1}$, neviyarni @ konselor.org ${ }^{2}$, \\ irdamurni241161@ gmail.com ${ }^{3}$
}

Received: May 10, 2020 Revised: May 13, 2020 Accepted: May 15, 2020

\begin{abstract}
ABSTRAK
Latar belakang penulisan artikel ini adalah perlunya informasi mengenai karakteristik perkembangan bahasa siswa sekolah dasar. Tujuan penulisan ini adalah untuk mengkaji karakteristik perkembangan bahasa siswa sekolah dasar. Penelitian ini merupakan penelitian studi kepustakaan yang mengkaji sebanyak 24 artikel yang berhubungan dengan karakteristik perkembangan bahasa siswa sekolah dasar yang terdapat pada database google scholar. Hasil pengkajian tersebut dijadikan sebagai referensi untuk menemukan karakteristik perkembangan bahasa siswa sekolah dasar. Hasil pengkajian ditemukan bahwa siswa sekolah dasar berada pada fase meniru dan memahami ucapan orang dewasa. Pada fase ini siswa juga telah memahami konsep cinta baik kepada orang dewasa maupun kepada lawan jenis. Hal ini menuntut guru untuk dapat melakukan dekteksi dini dan penyaringan bahasa agar tidak terjadi penyimpangan bahasa.
\end{abstract}

Kata Kunci: Karakteristik, Perkembangan, Bahasa .

\begin{abstract}
The background of writing this article is the need for information about the characteristics of language development of elementary school students. The purpose of this paper is to examine the characteristics of the language development of elementary school students. This research is a literature study that examines as many as 24 articles related to the characteristics of the language development of elementary school students contained in the Google Scholar database. The results of the study were used as a reference to find the characteristics of the language development of elementary school students. The results of the study found that elementary school students were in the phase of imitating and understanding adult speech. In this phase, students also understand the concept of love both to adults and to the opposite sex. This requires teachers to be able to carry out early detection and screening of language so that language deviations do not occur.
\end{abstract}

Keywords : Characteristics, Development, Language. 


\section{PENDAHULUAN}

Interaksi sosial penting bagi pelaksanaan kehidupan seseorang (Witarsa et al, 2018). Interaksi dapat dilakukan dengan proses komunikasi yang baik (Inah, 2015). Komunikasi dapat dilakukan baik dengan lisan maupun dengan tulisan yang melibatkan sistem bahasa. Interaksi tersebut akan dapat berjalan dengan baik apabila diasah semenjak dini termasuk pada usia sekolah dasar (Dewi, 2017).Proses interaksi yang melibatkan komunikasi yang aktif harus memperhatikan nilai yang berada di dalam masyarakat (Dewi, 2020). Nilai tersebut perlu diajarkan semenjak anak usia dini dan usia sekolah dasar agar dapat menjadi landasan yang kuat dan tertanam di dalam diri anak. Semua itu akan tergambar dalam proses berbahasa yang dibawakan oleh anak.

Kemampuan berbasa anak tidak didapat secara instant namun adanya proses yang dilalui secara bertahap dan berkembang yang dimulai dari lahir hingga anak menjadi dewasa (Dinihari, 2019). Perkembangan bahasa anak dimulai dari yang sederhana menuju tahap sempurna (Wulandari, 2018). Pada awalnya kemampuan berbahasa anak dimulai dari penyederhanaan dan penyesuaian ucapan orang dewasa yang dapat berupa penyesuaian fonologis (Julrissani, 2018). Maka disinilah peran pendidikan untuk dapat mengembangkan kemampuan berbahasa anak.

Undang-undang sistem pendidikan nomor 20 tahun 2003 menyatakan bahwa proses pembelajaran harus mengaktifkan segala bentuk dan kemampuan yang dimiliki oleh siswa. Hal ini termasuk mengembangkan kemampuan berbahasa meskipun kemampuan tersebut tidak secara nyata tertulis pada undang-undang tersebut. Namun pada kemampuan berbahasa menjadi hal penting dalam proses pendidikan dikarenakan sebagai alat komunikasi utama anak. Dengan berkembangnya kemampuan berbahasa naka akan dapat mewujudkan potensi diri yang ada pada anak. Tidak akan terjadi proses interaksi dalam sistem pendidikan apabila tidak adanya perkembangan kemampuan berbahasa anak. Oleh sebab guru disekolah dasar memiliki tanggung jawab yang besar terhadap perkembangan bahasa siswa sekolah dasar.

Untuk menjadi seorang guru harus memiliki empat komptensi utama guru yaitu kompetensi pedagogik, kompetensi kepribadian, kompetensi profesional, dan kompetensi sosial (Mulyani, 2017). Keempat kompetensi ini akan mampu membantu guru dalam mencapai tujuan pembelajaran yang ditetapkan pada undang- undang sistem pendidikan. Namun banyak kenyataan yang ditemui bahwa pada proses pembelajaran 
guru telah memaksimalkan kompetensi tersebut dan telah mengajarkan konsep bahasa yang baik namun pada kenyataannya masih ditemukan siswa yang menggunakan bahasa tidak secara terkontrol bahkan banyak yang cendrung menggunakan bahasa kotor seperti setan, anjing, babi dan lain sebagainya yang ditujukan kepada individu maupun sekelompok orang (Julrissani, 2018). Bagi siswa kelas rendah hal tersebut merupakan sebagai tiruan yang mereka dengar dan alami pada lingkungan tempat tinggal nya namun mereka tidak memahami arti dari perkataan tesebut. Namun bagi siswa kelas tinggi mereka sudah memahami arti dan makna perkataan tersebut namun mereka masih menggunakan kata-kata tersebut. Hal ini membuktikan bahwa adanya permasalahan yang terjadi pada proses perkembangan bahasa anak. Permasalahan ini perlu diatasi segera. Guru harus mampu membimbing kemampuan bahasa siswa yang sesuai dengan tahapan perkembangannya. Hal ini lah yang menjadi latar belakang penulisan artikel ini dengan tujuan untuk mengkaji proses perkembangan bahasa anak usia sekolah dasar agar guru memahami proses perkembangan siswa sekolah dasar.

\section{METODE}

Penelitian ini merupakan penelitian studi kepustakaan yang mengkaji sebanyak 24 artikel yang berhubungan dengan karakteristik perkembangan bahasa siswa sekolah dasar yang terdapat pada database google scholar. Hasil pengkajian tersebut dijadikan sebagai referensi untuk menemukan karakteristik perkembangan bahasa siswa sekolah dasar.

\section{HASIL DAN PEMBAHASAN}

\section{Pengertian Perkembangan Bahasa}

Perkembangan sering disamakan dengan pertumbuhan dan kematangan namun ketiga hal tersebut tidak dapat disamakan namun berhubungan erat (Benymin, 2020). Pertumbuhan merupakan proses perubahan ketahapan yang sempurna dengan menekankan aspek fisik (Yuhana and Aminy, 2019). Perkembangan merupakan bertambahnya kualitas yang behubungan dengan psikis menyuju kesempurnaan fungsional. Perkembangan merupakan perubahan yang dialami oleh individu yang dimulai dari masa prenatal hingga mencapai kematian (Burhaein, 2017). Perkemmbangan ini bertambahnya integritas fungsi jasmani menuju kedewasaan. 
Manusia pada proses kehidupannya merupakan makhluk sosial yang membutuhkan interaksi (Hantono and Pramitasari, 2018). Interaksi yang dilakukan dapat dijalankan melalui bahasa (Apriliyani and Rokhman, 2016). Oleh sebab itu diperlukan pemahaman terhadap perkembangan bahasa terutama guru sekolah dasar dalam menghadapi perkembangan bahasa siswa sekolah dasar. Guru harus dapat memperhatikan perkembangan bahasa siswa sekolah dasar seperti penggunaan bahasa yang sering dipakai oleh siswa sekolah dasar.

Bahasa memiliki berbagai bentuk variasi dan makna akibat dari berbagai variasi interaksi yang dialami oleh siswa (Mirna, 2020). Hal ini dikarenakan bahasa merupakan salah satu bentuk alat interaksi yang digunakan dapat menyampaikan pendapat, ide dan gagasan (Noermanzah, 2019). Bahasa itu sendiri dapat maknai sebagai bentuk alat komunikasi yang berbentuk lambangan yang berbunyi baik berupa tulisan maupun lisan yang bertujuan untuk komunikasi (Wicaksono, 2016). Bahasa dapat disampaaikan melalui proses bicara yang didasari oleh simbul verbal ataupun non verbal. Bahasa merupakan alat komunikasi yang dugunakan untuk bertukar pikiran, gagasan dan emosional. Setiap bahasa yang dihasilkan merupakan bentuk dari proses perkembangan bahasa anak. Perkembangan bahasa berkaitan dengan proses kematangan otak (Isna, 2019). Apabila kematang otak berkembang dengan baik maka kemampuan bahasa anak akan berkembang dengan baik.

Dari berbagai pengetian tersebut dapat disimpulkan bahwa kemampuan berbahasa merupakan proses siswa dalam mengekspresikan dirinya terhadap interaksi sosial dengan menggunakan simbol yang sesuai dengan aturan serta telah disepakati bersama dan didasari oleh kematangan otak sehingga anak mampu membedakan bahasa yang baik dan tidak baik untuk di ucapkan. Kedewasaan anak dalam berbahasa juga dipengaruhi oleh situasi dan kondisi lingkungan anak. Sehingga guru dan orang tua harus memastikan bahwa anak berada pada kondisi lingkungan yang baik agar proses perkembangan bahasa anak dapat berkembang dengan baik.

\section{Tahap Perkembangan Bahasa Anak}

Pada masa kehamilan anak sudah mulai berbahasa. Porses ini terjadi melalui saluran intrauterine. Setiap ucapan yang disampaikan oleh ibu maka akan tersampaikan kepada janis secara biologis. Hal ini dikarenakan pada masa janis anak 
sudah dapat mengenal suara ibu. Tidak hanya saja mengenal suara namun juga mengenal aroam, dan wajah. Oleh sebab itu bayi ketika lahir merasa nyaman berada di dekat ibu dari pada ayah. Oleh sebab itu lingkungan keluarga berpenagruh terhadap kemampuan bahasa anak.

Namun kemampuan bahasa anak dipengaruhi oleh beberapa faktor yaitu:

a. Faktor Kesehatan. Apabila anak sering mengaami gangguan terhadap alat pendengaran dan bicara maka akan menghambat kemampuan berbahasa siswa (Safitri, 2017).

b. Faktor Intelegensi. Anak yang memiliki kemampuan intelegensia yang tinggi maka akan memiliki kemampuan bahasa yang baik dan apabilan anak memliki intelegensia yang rendah maka anak akan mengalami kendala terhadap proses perkembangan bahasa anak (Poernomo, 2015).

c. Faktor sosial dan ekonomi. Beberapa penelitian membandingkan kemamuan berbahasa anak yang memiliki ekonomi kuat memiliki kemampuan bahasa yang tinggi dibandingkan dengan anak yang berekonomi rendah (Chamidah, 2009).

d. Jenis Kelamin. Jenis kelamin juga berpengaruh terhadap kemampuan berbahasa siswa. Perkembangan bahasa anak perempuan lebih cepat dibandingkan anak lakilaki (Kapoh, 2010).

e. Hubungan keluarga. Hubungan keluarga juga berpengaruh terhadap proses pekrkembangan bahasa siswa. Anak yang berasal dari keluarga yang harmonis memiliki kemampuan bahasa yang baik dibandingkan dengan anak yang memiliki keluarga tidak harmonis (Adriana, 2008).

Faktor-faktor ini lah yang menentukan proses perkembangan bahasa siswa. apabila orang dewasa memahami hal tersebut maka akan terciptalah anak yang memiliki kemampuan bahasa yang baik.

Setiap anak akan mengalami perkembangan bahasanya sendiri. Pakar perkembangan yang bernma erikson membagi proses perkembangan anak menjadi beberapa tahapan. Adapun tahapanya sebagai berikut:

a. Anak berumur 0-1 tahun / tahapan bersahabat vs menolak

Pada tahapan ini bayi akan sangat memerlukan kasih sayang. Bayi pada fase ini akan bersahabat dengan orang-orang yang berada dilingkunganya. Namun apabila kebutuhan bayi tidak terpenuhi maka bayi akan menolak lingkungan tersebut. 
b. Anak berumur 1-3 tahun / tahapan otonomi vs malu-malu

Pada masa ini anak akan merasa bangga apabila sudah mampu mendorang, membuka, memanjat dan lain sebagainya. Perasaan ini sebagai bentuk otnomi anak namun apabila anak sering dimanja oleh orang tua dalam beraktivitas maka anak akan malu-malu untuk bertindak.

c. Anak berumur (3-5 tahun) / tahapan inisiatif vc perasaan bersalah

Pada tahapan ini orang tua harus memberikan kebebasan kepada anak untuk melakukan inisiatifnya. Pada tahapan ini akan memberikan pertanyaan-pertanyaan yang diberikan kepada orang tua. Apabila orang tua tidak memberikan kebebasan dan menjawab pertanyaan maka anak akan memilliki rasa bersalah

d. Anak berumur 6- 11 tahun / tahapan perasaan produktif vs rendah diri

Pada tahapan anak sudah mulai berpikir secara deduktif. Pada tahapan ini anak akan paham dengan istilah cinta baik kepada orang tua maupun kepada lawan jenis. Pada tahapan ini anak akan termotivasi untuk melakukan perkerjaan secara cepat. Anak akan sangat merasa dihargai apabila diberikan hadiah. Namun pada anak yang mengalami gangguan mental akan cendrung memiliki perasaan rendah diri.

e. Anak berumur 12-18 tahun/ tahapan identitas vs kebingungan.

Pada tahapan ini anak sudah mulai masuk tahapan remaja. Anak pada tahapan ini sudah mampu memahami dirinya berdasarkan pengalaman yang dilauinya. Pada tahapan ini anak sudah mulai paham akan tanggungjawab yang diberikan (Krismawati, 2018).

Maka berdasarkan pemaparan tersebut dapat dipahami bahwa anak usia sekolah dasar berada pada renatan 7 sampai dengan 12 tahun. pada usia ini anak sudah paham dengan istilah cinta meskipun masih belum kompleks. Siswa sudah mampu memahami cinta sepeerti orang dewasa. Cinta tersebut dapat berupa cinta kepada orang tua dan lawan jenis. Pada masa ini juga akan terjadi proses persaingan memperebutkan perhatian lawan jenis. Maka pada tahapan inilah seorang guru harus memahami perkembangan anak. Anak secara alami akan mampu memahami dan mengingat segala sesuatu yang berhubungan dengan proses perkembanganya. Oleh sebab itu seorang guru harsu mampu memberikan stimulus dan respon kepada siswa dalam mengoreksi mau[un memperbaiki bahasa siswa yang tidak sesua dengan 
perkembangan dan aturan yang berlaku. Guru harus mampu memfilter bahasa agar proses perkembangan bahasa dapat dilakukan secara optimal.

\section{Problematika Bahasa yang Dialami Anak}

Banyak permasalahan bahasa yang sering di alami oleh anak. Hal ini sudah seharusnya menjadi perhatian khusus oleh orang dewasa (orang tua dan guru). Permasalahan bahasa anak tidak hanya sekedar menganggu proses pembelajaran namun juga berdampak kepada interaksi siswa terhadap lingkungannya. Permasalahan bahasa siswa dapat diketahui dari proses interaksi siswa didalam kelas (Widianto and Zulaeha, 2016). Biasanya permasalahan tersebut lahir dari adanya tuntutan yang datang dari lingkungan yang baru. Sehingga semakin besar tuntutan tersebut maka semakin besar resiko siswa mengalami perkembangan bahasa. Oleh sebab itu guru dan orang tua harus dapat mengetahui permasalahan bahasa anak semenjak dini.

Penyebab adanya gangguan perkembangan bahasa anak dapat berasal dari gangguan fisik seperti adanyan gangguan terhadat alat pendengaran dan alat berbicara yang menghambat lahirnya bahasa anak (Marissa, 2015). Penyimpangan bahasa juga menjadi penyebab adanya gangguan perkembangan bahasa anak. Penyimpangan ini terjadi akibat dari sering nya anak berinteraksi dengan orang yang lebih tua darinnya. Siswa sekolah dasar merupakan fase mendengar dan meniru. Pada umunya siswa sekolah dasar belum sepenuhnya mampu memahami makna setiap ucapan yang disampaikan namun pada siswa kelas tinggi sudah mulai memahaminya meskipun masih terdapat beberapa siswa yang belum mampu memahami sepenuhnya. Contohnya ketika ada siswa kelas tinggi tersebut mengejek siswa lain maka siswa akan memahami bahwa mengejek tersebut adalah termasuk bagian dari merendahkan diri seseorang. Kasus-kasus seperti ini apabila tidak diatasi segera maka akan berdampak kepada kualitas interaksi siswa. maka diperlukan deteksi dini dalam penanganan permasalahan tersebut agar siswa dapat menyaring setiap bahasa yang di ucapkan.

Siswa sekolah dasar banyak melihat dan meniru bahasa yang sering mereka lihat di televisi maupun sosial media (Rozalia, 2017). Meskipun pada telivisi dan sosial media pemerintah sudah mulai menyaring konten yang tidak sesuai dengan nilai dan budaya bangsa namun hal tersebut belum sepenuhnya maksimal dan masih 
terdapat celah dalam proses penyaringan sehingga masih banyak bahasa yang tidak layak untuk dikomsumsi. Maka disinilah peran guru dan orang tua untuk dapat mengawasi dan menjaga prialku anak agar anak terjaga dari penyimbangan bahasa yang terjadi.

\section{Simpulan}

Perkembangan bahasa anak usia sekolah dasar yang berada pada umur 6-12 tahun telah memahami makna kata yang diucapkan. Namun masih banyak ditemukan penyimpangan bahasa yang dilakukan. Selain itu juga anak sudah memahami bahasa cinta yang perlu di arahkan oleh guru kearah yang lebih baik.

\section{DAFTAR PUSTAKA}

Adriana, I. (2008). Memahami pola perkembangan Bahasa anak dalam konteks pendidikan. TADRIS: Jurnal Pendidikan Islam, 3(1), 1-10

Apriliyani, N., \& Rokhman, F. (2016). Strategi pilihan bahasa pengusaha industri di kecamatan ajibarang kabupaten banyumas. Seloka: Jurnal Pendidikan Bahasa dan Sastra Indonesia, 5(2), 184-191.

Benyamin, P. I., \& Gratia, Y. P. (2020). Pengembangan Model Pendidikan Agama Kristen Bagi Anak Korban Kemiskinan. Ecodunamika, 3(1),1-10

Burhaein, E. (2017). Aktivitas fisik olahraga untuk pertumbuhan dan perkembangan siswa SD. Indonesian Journal of Primary Education, 1(1), 51-58.

Chamidah, A. N. (2009). Deteksi dini gangguan pertumbuhan dan perkembangan anak. Jurnal pendidikan khusus, 5(2), 83-93.

Dewi, P. Y. A. (2020). Hubungan Gaya Komunikasi Guru Terhadap Tingkat Keefektifan Proses Pembelajaran. Purwadita: Jurnal Agama dan Budaya, 3(2), 71-78.

Dewi, Y. A. S. (2017). Korelasi Efektivitas Komunikasi dan Latar Belakang Etnis/Suku Orangtua Terhadap Perkembangan Bahasa Anak di Raudlatul Athfal Kabupaten Pasuruan. SELING: Jurnal Program Studi PGRA, 3(1),1-10.

Dinihari, Y., Wiyanti, E., \& Nazelliana, D. (2019). Meningkatkan Kemampuan Berbahasa Anak Usia Dini di Era Revolusi Industri 4.0. In Prosiding Seminar Nasional Pendidikan STKIP Kusuma Negara. 
Hantono, D., \& Pramitasari, D. (2018). Aspek perilaku manusia sebagai makhluk individu dan sosial pada ruang terbuka publik. Nature: National Academic Journal of Architecture, 5(2), 85-93.

Inah, E. N. (2015). Peran komunikasi dalam interaksi guru dan siswa. Al-TA'DIB: Jurnal Kajian Ilmu Kependidikan, 8(2), 150-167.

Isna, A. (2019). Perkembangan Bahasa Anak Usia Dini. Al Athfal: Jurnal Kajian Perkembangan Anak Dan Manajemen Pendidikan Usia Dini, 2(1), 62-69.

Julrissani, J. (2020). Karakteristik Perkembangan Bahasa dalam Berkomunikasi Siswa Sekolah Dasar di SD Muhammadiyah Karangbendo Yogyakarta. Edumaspul: Jurnal Pendidikan, 4(1), 72-87.

Kapoh, R. J. (2010). Beberapa Faktor Yang Berpengaruh Dalam Perolehan Bahasa. Jurnal Interlingua, 4, 87-95.

Krismawati, Y. (2018). Teori psikologi perkembangan erik h. erikson dan manfaatnya bagi tugas pendidikan kristen dewasa ini. KURIOS (Jurnal Teologi dan Pendidikan Agama Kristen), 2(1), 46-56.

Marisa, R. (2015). Permasalahan Perkembangan Bahasa dan Komunikasi Anak. JPsd (Jurnal Pendidikan Sekolah Dasar), 1(2), 47-55.

Mirna, W. (2020). Karakteristik Bahasa Guru Dalam Interaksi Belajar Mengajar Bahasa Indonesia Di Kelas XII MIPA 2 SMAN 1 Bangil Kabupaten Pasuruan. Lingue: Bahasa, Budaya, dan Sastra, 1(1), 54-67.

Mulyani, F. (2017). Konsep Kompetensi Guru dalam Undang-Undang Nomor 14 Tahun 2005 Tentang Guru dan Dosen (Kajian Ilmu Pendidikan Islam). Jurnal Pendidikan UNIGA, 3(1), 1-8.

Noermanzah, N. (2019). Bahasa sebagai alat komunikasi, citra pikiran, dan kepribadian. In Seminar Nasional Pendidikan Bahasa dan Sastra (pp. 306-319).

Poernomo, D. I. S. H., \& Paskarinda, E. P. (2015). Faktor Kesehatan, Intelegensi, Dan Jenis Kelamin Mempengaruhi Gangguan Perkembangan Bahasa Anak Prasekolah. Jurnal Stikes RS Baptis Kediri, 8(1).

Safitri, Y. (2017). Faktor-faktor yang berhubungan dengan perkembangan bahasa balita di UPTD kesehatan Baserah tahun 2016. Jurnal Obsesi: Jurnal Pendidikan Anak Usia Dini, 1(2), 148-155.

Widianto, E., \& Zulaeha, I. (2016). Pilihan bahasa dalam interaksi pembelajaran bahasa indonesia bagi penutur asing. Seloka: Jurnal Pendidikan Bahasa dan Sastra Indonesia, 5(2), 124-135. 
Witarsa, R., Hadi, R. S. M., Nurhananik, N., \& Haerani, N. R. (2018). Pengaruh Penggunaan Gadget Terhadap Kemampuan Interaksi Sosial Siswa Sekolah Dasar. Pedagogik (Jurnal Pendidikan Sekolah Dasar), 6(1), 9-20.

Wulandari, D. I. (2018). Pemerolehan bahasa Indonesia anak usia 3-5 tahun di PAUD Lestari desa Blimbing kecamatan Paciran kabupaten Lamongan. Lingua Franca: Jurnal Bahasa, Sastra, dan Pengajarannya, 2(1),1-10

Yuhana, A. N., \& Aminy, F. A. (2019). Optimalisasi peran guru pendidikan agama Islam sebagai konselor dalam mengatasi masalah belajar siswa. Jurnal Penelitian Pendidikan Islam, [SL], 7(1), 79-96. 